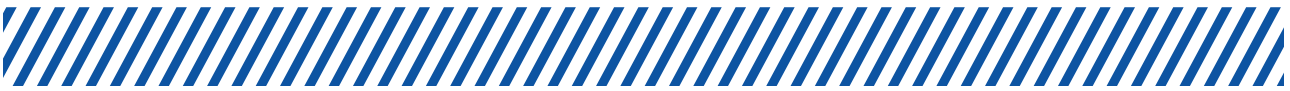

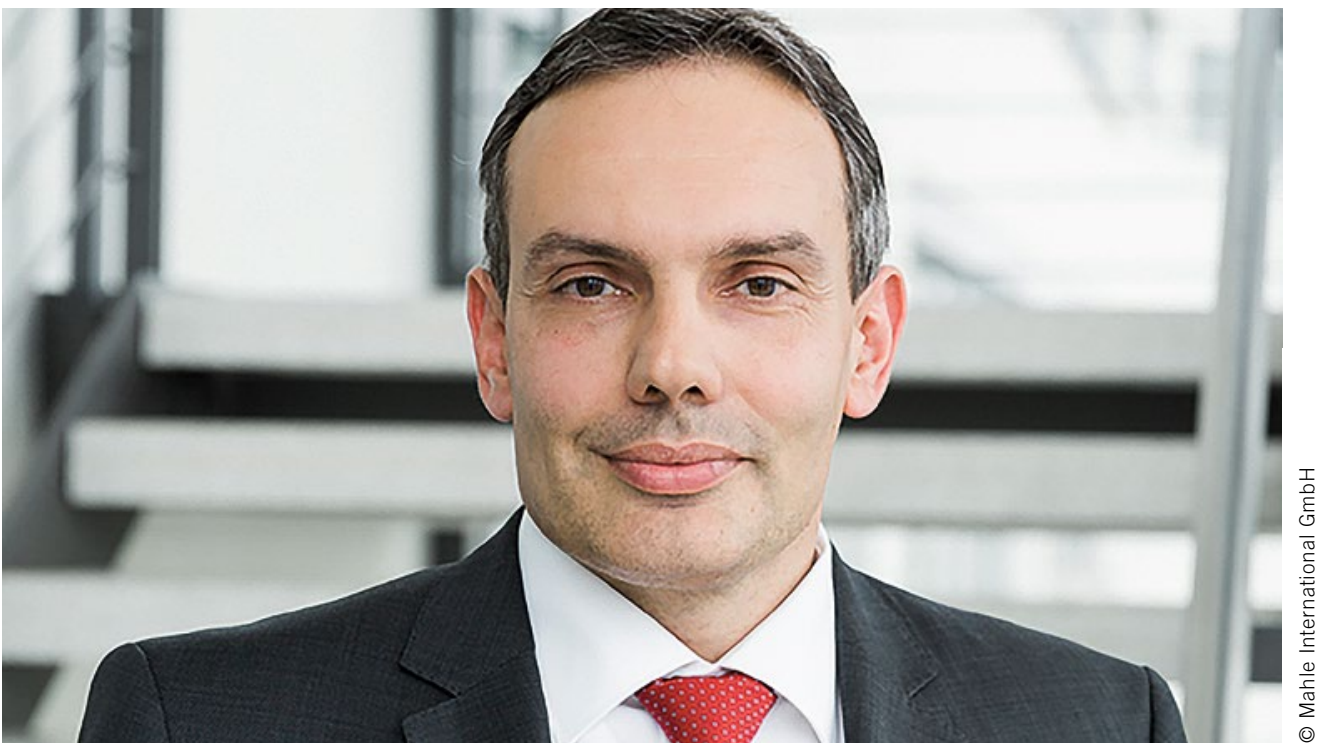

Dr. Martin Berger

Leiter Forschung und Voraus-

entwicklung bei Mahle

\section{Wie der Durchbruch im klimaneutralen Schwerlastverkehr gelingen kann}

Die Herausforderungen an die Mobilität der Gegenwart und Zukunft steigen. Individuelle Mobilitätsbedürfnisse, wirtschaftliche Anforderungen und politische Vorgaben machen die Gestaltung nachhaltiger Mobilität zu einer komplexen Aufgabe. Insbesondere Fahrzeuge mit Verbrennungsmotoren haben es zunehmend schwerer. Rund um die Welt kündigen sich Verbote oder verschärfte Richtlinien an, die insbesondere Fahrzeuge mit diesem Antrieb treffen werden.

Um die enormen Folgen des Klimawandels zu bewältigen und zu mindern, benötigen wir als Gesellschaft all unsere Ideen, Kräfte, Ressourcen und Technologien. Es liegt auf der Hand, dass wir dabei nur mit einem vielfältigen Mix an klimaschonenden Antriebstechnologien Erfolg haben können. Denn Mobilitätsbedürfnisse, Fahrprofile und gesetzliche Rahmenbedingungen sind vielfältig und erfordern unterschiedliche Antriebstechnologien.

Fokussieren wir uns ausschließlich auf batterieelektrische Mobilität, lassen wir wirksame Hebel hin zu einem $\mathrm{CO}_{2}$-neutralen gewerblichen Verkehr außer Acht. Die Anforderungen an Nutzfahrzeuge sind grundlegend anders als die an Personenkraftwagen. Die hier erforderlichen Fahrleistungen lassen sich schlicht nicht abbilden, da die erforderlichen Batterien zu schwer, zu groß und zu teuer sind - all das mit entscheidenden Auswirkungen auf Nutzlast, Kosten und damit die Wirtschaftlichkeit. Die Wasserstofftechnologie eröffnet uns hier Wege, um schwere Nutzfahrzeuge im Langstreckenbetrieb klimaneutral zu machen.

Mahle leistet mit Komponenten für Brennstoffzelle und Wasserstoffverbrennung im Nutzfahrzeug bereits heute einen großen
Beitrag. Seit über einer Dekade sind wir mit unseren Bauteilen in Fahrzeugen mit Brennstoffzellenantrieb vertreten - sei es in der Filtration, dem Thermomanagement oder im komplexen Luftpfad. Wichtig für den Durchbruch von Wasserstoff als Energieträger im Schwerlastverkehr sind heute vor allem zwei Dinge: der Ausbau einer Infrastruktur für die Erzeugung und Verteilung von Wasserstoff sowie eine Stückkostensenkung auf Fahrzeugebene. Beides erfordert in erster Linie Investitionssicherheit für Unternehmen. Diese Sicherheit ist gegeben, wenn alle klimafreundlichen, nachhaltigen Antriebsarten gefördert werden und sich die Branche auf eine klare und kohärente Emissionsgesetzgebung verlassen kann.

In der Vergangenheit sind wir - wie viele andere Zulieferer auch - ganz gezielt in der Entwicklung in Vorleistung gegangen. Unser Ziel war dabei, den Boden für klimaneutrale Wasserstoffantriebe zu bereiten. Wir stehen heute voll hinter den Pariser Klimazielen. Strengere Emissionsrichtlinien allein reichen jedoch nicht aus, um die initiale Schwelle für den breiten Einsatz von Wasserstoff in Nutzfahrzeugen zu überspringen. Politik und Wirtschaft müssen hier gemeinsam handeln. Und zwar so, dass die Branche die Möglichkeit bekommt, ökologisch, ökonomisch und nicht zuletzt auch sozial nachhaltige Lösungen zu entwickeln und in den Markt zu bringen. Eine ausschließlich auf Restriktionen setzende Politik greift hier zu kurz. Wirtschaft und Politik müssen deswegen ihren Dialog intensivieren - nur so können wir gemeinsam ganzheitlich nachhaltige Lösungswege für einen klimaneutralen Schwerverkehr finden. 